\title{
Investigation of rs1800469 and rs1800468 Polymorphisms of the TGF- $\beta 1$ Gene in Women with Pre-eclampsia
}

\author{
Andrezza Cristina Cancian Hortolani 1 \\ Sarah Cristina Sato Vaz Tanaka 2 \\ Marina Carvalho Paschoini 3 \\ Marly Aparecida Spadotto Balarin 4
}

\footnotetext{
1, 2, 4 Departamento de Patologia Genética e Evolução. Universidade Federal do Triângulo Mineiro. Praça Manoel Terra, 330, Abadia, Uberada, MG, Brasil. CEP: 38025-180. E-mail: balarin@mednet.com.br
}

3 Departamento Materno Infantil. Universidade Federal do Triângulo Mineiro. Uberada, MG, Brasil.

\begin{abstract}
Objectives: to verify the contribution of polymorphisms rs 1800469 and rs 1800468 of the $T G F-\beta 1$ gene and the risk factors for the pre-eclampsia development.

Methods: this is a case-control study with 257 women from the Uberaba region of Minas Gerais were selected, 88 of them were in the pre-eclampsia group and 169 in the control group. Genotyping was performed by allelic discrimination using the real-time PCR technique. The odds ratio and the $95 \%$ confidence interval were used to evaluate the probability of the polymorphisms studied contributing for the pre-eclampsia development. The logistic regression analysis was performed to evaluate the relation among family recurrence, smoking, primiparity and the presence of polymorphic alleles and susceptibility of preeclampsia.

Results: no association was found between polymorphisms rs 1800469 and rs 1800468 of the TGF- $\beta 1$ gene and pre-eclampsia. The logistic regression analysis was statistically significant for family recurrence, showing that women with a family history of pre-eclampsia and primiparity are at an increased risk of developing the disease.

Conclusions: no association was found between polymorphisms rs 1800469 and rs 1800468 of the TGF- $\beta 1$ and pre-eclampsia gene. Factors such as family history and primiparity were associated to the risk of developing pre-eclampsia.
\end{abstract}

Key words Pre-eclampsia, Transforming Growth Factors, Genetic polymorphism 


\section{Introduction}

Pre-eclampsia (PE) is a hypertensive syndrome specific to human pregnancy whose clinical signs and symptoms occur after the twentieth week of pregnancy. It is characterized by the increased blood pressure levels (systolic blood pressure $\geq 140 \mathrm{mmHg}$ and diastolic blood pressure $\geq 90 \mathrm{mmHg}$, measured on two occasions with intervals of at least 4 hours between them) and proteinuria $>300 \mathrm{mg} / 24$ hours or $\geq 1+$ protein detected in the urine analysis, type I). 1

The risk factors the predispose for the onset of PE include the extreme of reproductive age, primiparity, extended time between pregnancies, increased body mass index, family history of PE, pre-existing hypertension, obesity, metabolic syndrome and diabetes mellitus. ${ }^{2}$

There is no consensus on what triggers $\mathrm{PE}$, and it is considered to be the disease of theories. However, it is known that there is the participation of genetic, inflammatory and immunological factors. Among the genetic factors, the interaction between gene-environment occurs more in relatives of affected individuals than in the general population, since members of the same family share besides the genetic information, share the same environmental factors. ${ }^{3}$

In concern of the immunological factors, many cytokines appear as candidates in the development of PE, including the Transforming Growth Factor Beta-1 $(T G F-\beta 1) .{ }^{4}$

The $T G F-\beta 1$ is a multifunctional cytokine that has the potential to alter the balance between the syncytiotrophoblast and the invasive cytotrophoblast, in which the normal pregnancy development depends and contributes to the regulation of the maternal immune response against the fetal allograft. 5 The mean levels of $T G F-\beta 1$ seem to increase in patients with $\mathrm{PE}$ compared to normotensive women. 6

Polymorphisms rs1800468 and rs1800469 are located in the promoter region of the TGF- $\beta 1$ gene and have the function of regulating expression levels of protein and are capable of triggering alterations in the splicing sites, ${ }^{7}$ due to the exchange of the bases of these two variants in the beginning of the gene transcription. 8

The presence of the polymorphic allele A of the polymorphism rs1800468 interrupts a binding consensus of the protein to the Camp Response Element (CRE) nuclear transcription factor, which causes a lower production of the total $T G F-\beta 1$ in the circulation. ${ }^{9}$ Also, polymorphism rs 1800469 appears to be associated to an increased transcriptional activity, 10 raising circulating levels of $T G F-\beta 1.8,9$

Considering that the $T G F-\beta 1$ gene exerts its influence in numerous of physiological and pathophysiological processes, such as fetal development, inflammatory processes, immune system suppression and the appearance of hypertension, it is interesting to evaluate the contribution of polymorphisms in this gene and the development of PE. 11

Therefore, the objective of this work was to verify the contribution of polymorphisms rs 1800469 and rs 1800468 of the $T G F-\beta 1$ gene and the risk factors for the PE development.

\section{Methods}

It is a case-control study, where 257 women aged 1845 years old were selected, with no history of hypertension, kidney or other chronic diseases. The study group was consisted of 88 women diagnosed with $\mathrm{PE}$ according to the classification criteria of the American College of Obstetricians and Gynecologists. 1 The mean age of the study group was 27.5 years old $( \pm 6.6)$, the mean systolic blood pressure (SBP) was $155.4 \mathrm{mmHg}( \pm 22.4)$ and diastolic blood pressure (DBP) was $106.6 \mathrm{mmHg}$ ( \pm 14.6). In relation to smoking, $12.5 \%$ of the PE group were smokers and $27.4 \%$ of the study group had a family history of PE. The control group was consisted of 169 women without any type of intercurrence. The mean age of the control group was 31.8 years old $( \pm 7.8)$, the mean SBP was $114.3 \mathrm{mmHg}( \pm 11.6)$ and the DBP was $75.6 \mathrm{mmHg}( \pm$ 13.6). Regarding to smoking, $14.6 \%$ of the control group were smokers and the family history with PE was $5.3 \%$.

All the participants were selected at the Maria da Glória Ambulatory and/or at the Hospital de Clinicas da Universidade Federal do Triângulo Mineiro (HCUFTM) (Clinical Hospital of the Federal University in Triângulo Mineiro) and had to sign the Consent Form Term (TCLE). This project was approved by the Ethics and Research Committee at the UFTM under the document number: CEP/UFTM-CAAE 44460115.1.0000.5154

$10 \mathrm{~mL}$ of peripheral blood were collected from each study participant and the DNA extraction was performed by using the phenol-chloroform method. 12

Genotyping of the samples for the polymorphisms rs 1800469 and $\mathrm{rs} 1800468$ of the $T G F-\beta 1$ gene was done by real-time PCR allelic discrimination with TaqMan $^{\circledR}$ hydrolysis probes (Applied Biosystems, USA), (Numbers of the assays: 
C8708473_10; C8708474_20, respectively). The equipment used for genotyping was Step One Plus (AB) and the conditions for each cycle were: $95^{\circ} \mathrm{C}$ for 10 minutes and 40 amplification cycles of $95^{\circ} \mathrm{C}$ for 15 seconds and $60^{\circ} \mathrm{C}$ for 1 minute. At each cycle, the equipment analyzed the fluorescence emitted from the wild and mutant alleles, labeled as FAM and VIC.

The genetic models and haplotypes were analyzed by using SNPStat software. The Chi-square test $\left(\chi^{2}\right)$ was used to test whether the genotypic distributions followed the Hardy-Weinberg Equilibrium (HWE). The multiple logistic regression model was used to determine the effect of risk factors and the PE. The models included the following data: smoking habit (reference: nonsmoker), family history of PE (reference: no), primiparity (reference: no), presence of the polymorphic allele $\mathrm{T}$ and $\mathrm{A}$ (reference: no). The results of the logistic regression model were presented in Odds Ratio (OR) and 95\% confidence intervals $(95 \% \mathrm{CI})$. Statistical power presented $80 \%$ for detection association using G POWER 3.1 software and the level of significance considered was $5 \%(p \leq 0.05)$.

\section{Results}

The analysis of the genetic models for polymorphisms rs 1800469 and rs 1800468 of the $T G F-\beta 1$ gene is shown in table 1.

For polymorphism rs 1800469 , no statistically significant difference was found in any of the genetic models analyzed (Codominance: $\mathrm{p}=0.93$, Dominance: $p=0.78$, Recessive: $p=0.87$ and Overdominance: $p=0.70)$. Both groups are found in the Hardy-Weinberg Eequilibrium (PE: $\chi^{2}=0.24$;

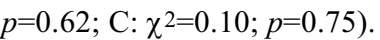

Table 1

Analysis of the genetic models for the polymorphisms rs1800469 and rs1800468 of the TGF- $\beta 1$ gene and Pre-eclampsia.

\begin{tabular}{|c|c|c|c|c|c|c|c|}
\hline \multirow{2}{*}{ Model } & \multirow{2}{*}{ Genotype } & \multicolumn{2}{|c|}{ Case } & \multicolumn{2}{|c|}{ Control } & \multirow{2}{*}{ OR $(95 \%$ IC) } & \multirow{2}{*}{$p$} \\
\hline & & $\mathrm{n}$ & $\%$ & $\mathrm{n}$ & $\%$ & & \\
\hline \multicolumn{8}{|l|}{ rs1800469 } \\
\hline \multirow[t]{3}{*}{ Codominance } & $\mathrm{C} / \mathrm{C}$ & 28 & 34.6 & 56 & 34.4 & 1.00 & 0.93 \\
\hline & $\mathrm{C} / \mathrm{T}$ & 40 & 49.4 & 72 & 46.8 & $0.90(0.50-1.63)$ & \\
\hline & $\mathrm{T} / \mathrm{T}$ & 13 & 16.1 & 26 & 16.9 & $1.00(0.45-2.24)$ & \\
\hline \multirow[t]{2}{*}{ Dominance } & $\mathrm{C} / \mathrm{C}$ & 28 & 34.6 & 56 & 36.4 & 1.00 & 0.78 \\
\hline & $\mathrm{C} / \mathrm{T}-\mathrm{T} / \mathrm{T}$ & 53 & 65.4 & 98 & 63.6 & $0.92(0.53-1.62)$ & \\
\hline \multirow[t]{2}{*}{ Recessive } & $\mathrm{C} / \mathrm{C}-\mathrm{C} / \mathrm{T}$ & 68 & 84 & 128 & 83.1 & 1.00 & 0.87 \\
\hline & $\mathrm{T} / \mathrm{T}$ & 13 & 16.1 & 26 & 16.9 & $1.06(0.51-2.20)$ & \\
\hline \multirow[t]{2}{*}{ Over-dominance } & $\mathrm{C} / \mathrm{C}-\mathrm{T} / \mathrm{T}$ & 41 & 50.6 & 82 & 53.2 & 1.00 & 0.70 \\
\hline & $\mathrm{C} / \mathrm{T}$ & 40 & 49.4 & 72 & 46.8 & $0.90(0.53-1.54)$ & \\
\hline \multicolumn{8}{|l|}{ rs1800468 } \\
\hline \multirow[t]{3}{*}{ Codominance } & $\mathrm{G} / \mathrm{G}$ & 84 & 95.5 & 158 & 93.5 & 1.00 & 0.59 \\
\hline & G/A & 4 & 4.5 & 10 & 5.9 & $1.33(0.40-4.37)$ & \\
\hline & $A / A$ & 0 & 0.0 & 1 & 0.6 & NA (0.00-NA) & \\
\hline \multirow[t]{2}{*}{ Dominance } & $\mathrm{G} / \mathrm{G}$ & 84 & 95.5 & 158 & 93.5 & 1.00 & 0.52 \\
\hline & G/A-A/A & 4 & 4.5 & 11 & 6.5 & $1.46(0.45-4.73)$ & \\
\hline \multirow[t]{2}{*}{ Recessive } & G/G-G/A & 88 & 100.0 & 168 & 99.4 & 1.00 & 0.36 \\
\hline & $\mathrm{A} / \mathrm{A}$ & 0 & 0.0 & 1 & 0.6 & NA (0.00-NA) & \\
\hline \multirow[t]{2}{*}{ Over-dominance } & $\mathrm{G} / \mathrm{G}-\mathrm{A} / \mathrm{A}$ & 84 & 95.5 & 159 & 94.1 & 1.00 & 0.64 \\
\hline & $\mathrm{G} / \mathrm{A}$ & 4 & 4.5 & 10 & 5.9 & $1.32(0.40-4.34)$ & \\
\hline
\end{tabular}

$\mathrm{OR}=$ Odds ratio;

Multiple Logistic Regression. 
Table 2

Prevalence of the polymorphisms rs1800469 and rs1800468 haplotypes of the TGF- $\beta 1$ gene of women with preeclampsia and the control group.

\begin{tabular}{lcccc}
\hline Haplotype & PE group & C group & OR $(-95 \% \mathrm{Cl})$ & $\boldsymbol{p}$ \\
\hline G-C & 0.569 & 0.560 & 1.00 & - \\
G-T & 0.408 & 0.404 & $1.01(0.68-1.50)$ & 0.95 \\
A-C & 0.022 & 0.035 & $1.54(0.50-4.73)$ & 0.46 \\
A-T & 0.0 & 0.0 & - & - \\
\end{tabular}

$\mathrm{OR}=$ Odds ratio; $\mathrm{PE}$ group= Pre-eclampsia group; $\mathrm{C}$ group= Control group; $\mathrm{Cl}=$ confidence interval. Algorithm EM

Table 3

Analysis of the risk factors contribution between Pre-eclampsia and the control group.

\begin{tabular}{|c|c|c|c|c|c|c|c|}
\hline \multirow{2}{*}{$\begin{array}{l}\text { Variable } \\
\text { analyzed }\end{array}$} & \multicolumn{2}{|c|}{ PE } & \multicolumn{2}{|c|}{ C } & \multirow{2}{*}{ OR } & \multirow{2}{*}{$(95 \%) \mathrm{Cl}$} & \multirow{2}{*}{$p$} \\
\hline & $\mathrm{n}$ & $\%$ & $n$ & $\%$ & & & \\
\hline Smoking & & & & & 1.82 & $0.318-0.680$ & 0.496 \\
\hline Yes & 10 & 12.2 & 23 & 14.8 & & & \\
\hline No & 72 & 87.8 & 132 & 85.2 & & & \\
\hline Family history & & & & & 17.76 & $1.984-4.354$ & $<0.001$ \\
\hline Yes & 22 & 26.8 & 9 & 5.8 & & & \\
\hline No & 60 & 73.2 & 146 & 94.2 & & & \\
\hline Primiparity & & & & & 19.32 & $2.163-5.311$ & $<0.001$ \\
\hline Yes & 30 & 36.6 & 11 & 7.1 & & & \\
\hline No & 52 & 63.4 & 144 & 92.9 & & & \\
\hline \multicolumn{8}{|l|}{ Polymorphisms } \\
\hline rs1800469 & & & & & 2.25 & $0.147-0.432$ & 0.665 \\
\hline $\mathrm{CC}$ & 29 & 35.4 & 56 & 36.1 & & & \\
\hline CT-TT & 53 & 64.6 & 99 & 63.9 & & & \\
\hline rs1800468 & & & & & 2.13 & $0.674-0.924$ & 0.355 \\
\hline GG & 78 & 95.1 & 144 & 92.9 & & & \\
\hline GA-AA & 4 & 4.9 & 11 & 7.1 & & & \\
\hline
\end{tabular}

$\mathrm{OR}=$ Odds ratio; $\mathrm{Cl}$ : Confidence Interval; $\mathrm{C}=$ control; $\mathrm{PE}=$ Pre-eclampsia. Multiple Logistic Regression 
For the polymorphism rs1800468, also no statistically significant difference was found in any of the genetic models analyzed (Codominance: $p=0.59$, Dominance: $p=0.52$, Recessive: $p=0.36$ and Overdominance: $p=0.64)$. Both groups are found in the Hardy-Weinberg Equilibrium (PE: $\chi^{2}=3.12 ; p=0.07$; $\mathrm{C}: \chi^{2}=0.048 ; p=0.82$ ).

The prevalence of the polymorphisms haplotypes rs 1800469 and rs 1800468 of the $T G F-\beta 1$ gene is shown in table 2 and no statistically significant difference was observed.

The logistic regression analysis among the known risk factors for the development of PE can be observed in table 3. A statistically significant difference was observed for family recurrence $(p<0.001)$ and primiparity $(p<0.001)$ of $\mathrm{PE}$, indicating that these factors are involved in the development of pre-eclampsia.

\section{Discussion}

This present work investigated the polymorphisms rs 1800469 and rs 1800468 and the region promoter of the TGF- $\beta 1$ gene and the PE susceptibility.

The genetic models test (codominance, dominance, recessivity and over-dominance) did not find an association between the polymorphism rs 1800469 of the TGF- $\beta 1$ gene and PE. Our results differ from those found by Deepthi et al.,13 who analyzed the polymorphism rs 1800469 of the $T G F-\beta 1$ gene with a sample of 469 Native Indian women, of those, 239 were in the group with PE and 230 in the control group. These authors demonstrated an association between the over-dominant model and observed that the TT genotype predisposes to PE, whereas the CT genotype seems to have a protective effect regarding the development of this disease. These results may have been found because the sample is larger in relation to the present study and due to the Indian population which is genetically homogeneous, but this is not the case of the Brazilian population.

For the polymorphism rs 1800468 of the $T G F-\beta 1$ gene, the data regarding the analysis of genetic models that could be related to the results obtained in this present study were not found. Even this is a pioneer study, in the type of analysis, no statistically significant association was found between the inheritance model and the PE susceptibility.

In this current study, no statistically significant difference was observed between the haplotype prevalence of polymorphisms rs1800469 and rs 1800468 of the $T G F-\beta 1$ gene and PE.

Aguilar-Duran et al.14 analyzed a Mexican study, the haplotypes of three polymorphisms rs 1800469 , rs 1800468 and rs 1800470 of the $T G F-\beta 1$ gene and, in this case, a moderate imbalance binding was found. The most frequent haplotype was rs $1800468 \mathrm{G} / \mathrm{rs} 1800469 \mathrm{C} / \mathrm{rs} 1800470 \mathrm{C}$, however, this result was not associated to the development of PE.

The study done by Deepthi et al. 13 analyzed the polymorphism rs1800470 and rs1800469 of the haplotypes and the predisposition to develop PE and found that the C-C and T-T haplotypes are associated to the increased susceptibility of this disease.

For the logistic regression analysis, it was observed that women with a family history of PE had a risk of developing the disease by increasing 17 times higher when compared to women without family recurrence. These results are according to those performed in Norway and the United Kingdom where daughters of women who had PE were twice as likely to develop the disease compared to women with no family history. The data from the United Kingdom also showed that women who were not born from pregnancy with PE, but reported a family history of this disease were at greater risk than women without a family history. 15,16

Mutze et al.17 also observed this hereditary component, showing that 25 to $31 \%$ of daughters of women with PE develop this disease in their pregnancies. Cnattingius et al. ${ }^{3}$ suggested that about $67 \%$ of the PE susceptibility is caused by genetic factors, while $32 \%$ are of several factors, reinforcing the multifactorial nature of $\mathrm{PE}$.

In addition to the family history of PE, the logistic regression analysis showed that primiparous women present an increased risk of nineteen times to develop PE when compared to women with more than two pregnancies. These results are similar to those by Khader et al., 18 observed that women in Jordanian had a twice the increased risk in developing PE in the first pregnancy than in later ones. Hernandez-Dias et al.19 also showed that multiparous women with no history of PE had a $1 \%$ risk of developing the disease, while women with PE in one or two consecutive pregnancies presented a 15$30 \%$ risk of recurrence, respectively.

This increase in the risk of PE in primiparous women can be explained by the immaturity of the maternal immune system. The increase of the PE in primiparous can be justified by the reduction of exposed time of the paternal antigens; thus, the development of the necessary immunological tolerance to the fetal allograft is impaired, occurring rejection, and resulting to an increased susceptibility of PE. 20,21

Thus, there are a few data in the world literature on the role of the polymorphisms rs1800469 and 
rs 1800468 of the $T G F-\beta 1$ gene and the susceptibility of PE. It is known that this disease is a complex disorder with clinical severity variable.1,22 $\mathrm{PE}$ is a multigenic disease, so it is expected that an involvement of several genes associated to its developmental mechanisms will occur. Consequently, studies with different genes are necessary in an attempt to understand the real role of the genetic factors in the etiology of PE. It is noteworthy to mention that studies that evaluate genetic polymorphisms and disease susceptibility in the Brazilian population are complex due to the genetic heterogeneity of our population, what does not occur in European and Asian populations. 23,24

Therefore, the present study found no association between polymorphisms of the $T G F-\beta 1$ gene, positions rs1800469 and rs1800468 and PE. However, factors such as family history and primiparity were associated with increased risk of developing PE. Although, further genetic studies are needed to understand the genesis of PE.

\section{References}

1. American College of Obstetricians and Gynecologists, Task Force on Hypertension in Pregnancy. Hypertension in pregnancy. Report of the American College of Obstetricians and Gynecologists' task force on hypertension in pregnancy. Obstet Gynecol. 2013; 122 (5): 1122.

2. Berry C, Atta MG. Hypertensive disorders in pregnancy. World J Nephrol. 2016; 6 (5): 418-28.

3. Cnattingius S, Reilly M, Pawitan Y, Lichtenstein P. Maternal and fetal genetic factors account for most of familial aggregation of preeclampsia: a population-based Swedish cohort study. Am J Med Genet. 2004; 103A (4): 365-71

4. Crome SQ, Wang AY, Levings MK. Translational minireview series on Th17 cells: function and regulation of human $\mathrm{T}$ helper 17 cells in health and disease. ClinExpImmunol. 2010; 159 (2): 109-19.

5. Power LL, Popplewell EJ, Holloway JA, Diaper ND, Warner JO, Jones CA. Immunoregulatory molecules during pregnancy and at birth. J ReprodImmunol. 2002; 56 (1-2): 19-28.

6. Khani M, Amani D, Taheripanah R, Sanadgol N, Feizollahzadeh S, Rahmani Z. Transforming growth factor beta-1 (TGF- $\beta 1)$ gene single nucleotide polymorphisms (SNPs) and susceptibility to pre-eclampsia in Iranian women: A case-control study. Pregnancy Hypertens. 2015; 5(4): 267-72.

7. Loeys BL, Schwarze U, Holm T, Callewaert BL, Thomas GH, Pannu H, De Backer JF, Oswald GL, Symoens S, Manouvrier S, Roberts AE, Faravelli F, Greco MA, Pyeritz RE, Milewicz DM, Coucke PJ, Cameron DE, Braverman AC, Byers PH, DePaepe AM, Dietz HC. Aneurysm syndromes caused by mutations in the TGF-beta receptor. N Engl J Med. 2006; 355 (8): 788-98.

8. Grainger DJ, Heathcote K, Chiano M, Snieder H, Kemp PR, Metcalfe JC, Carter ND, Spector TD. Genetic control of the concentration of transforming growth factor type beta1. Hum Mol Genet. 1999, 8 (1): 93-7.

9. Syrris P, Carter ND, Metcalfe JC, Kemp PR, Graiger DJ, Kaski JC, Crossman DC, Francis SE, Gunn J, Jeffery S,
Heathcote K. Transforming growth factor-b1 gene polymorphisms and coronary artery disease. Clinical Science. 1998; 95 (6): 659- 67

10. Luedecking EK, Dekosky ST, Mehdi H, Ganguli M, Kamboh MI. Analysis of genetic polymorphisms in the transforming growth factor betal gene and the risk of Alzheimer's disease. Hum Genet. 2000; 106 (5): 565-9.

11. Kajdaniuk D, Marek B, Borgiel-Marek H, Kos-Kudla B. Vascular endothelial growth factor (VEGF) - part 1: in physiology and pathophysiology. Endokrynol Pol. 2011; 62 (5): 444-5.

12. Sambrook J, Fritsch EF, Maniatis TE. Molecular Cloning, a laboratory manual. New York: Cold Spring Harbor; 1989.

13. Deepthi G, Chaithri PK, Latha P, Rani VU, Rahman PF, Jahan P. TGFB1 Functional Gene Polymorphisms (C-509T and T869C) in the Maternal Susceptibility to Pre-eclampsia in South Indian Women. Scand J Immunol. 2015; 82 (4): 390-7.

14. Aguilar-Duran M, Salvador-Moysén J, Galaviz-Hernandez C, Vásquez-Alaniz F, Sandoval-Carrillo AA, VelásquezHernandez N, Salas-Pacheco JM. Haplotype analysis of TGF-b1 gene in a preeclamptic population of northern Mexico. Pregnancy Hypertension: An International Journal of Women's Cardiovascular Health. 2014; 4 (1): 14-8.

15. Skjaerven R, Vatten LJ, Wilcox AJ, Ronning T, Irgens LM, Lie RT. Recurrence of pre-eclampsia across generations: exploring fetal and maternal genetic components in a population based cohort. BMJ. 2005; 331 (7521): 877.

16. Ayorinde AA, Bhattacharya A. Inherited predisposition to preeclampsia: Analysis of the Aberdeen intergenerational cohort. Pregnancy Hypertens. 2017; 8: 37-41.

17. Mütze S, Rufnik-Shöneborn S, Zerres K, Rath W. Genes and the preeclampsia syndrome. J Perinat Med. 2007; 36 (1): $154-8$.

18. Khader YS, Batieha A, Al-Njadat RA, HijaziI SS. Preeclampsia in Jordan: incidence, risk factors, and its associated maternal and neonatal outcomes. J Matern Fetal Neonatal Med. 2017; 8: 1-7. 
19. Hernandez-Dias S, Toh S, Cnattingius S. Risk of preeclampsia in first and subsequent pregnancies: prospective cohort study. BMJ. 2009; 18 (338): 2255.

20. Hernández-Valencia M, Saldaña Quezada L, Alvarez Muños M, Valdez Martínez E. Barrier family planning methods as risk factor which predisposes to preeclampsia GinecolObstet Mex. 2000; 68: 333-8.

21. Saftlas AF, Rubenstein L, Prater K, Harland KK, Field E, Triche EW. Cumulative exposure to paternal seminal fluid prior to conception and subsequent risk of preeclampsia. J ReprodImmunol. 2014; 101-102: 104-10.

22. Dhariwal NK, Lynde GC. Update in the Management of Patients with Preeclampsia. Anesthesiol Clin. 2017; 35 (1) 95-106.

Received on May 22, 2017

Final version presented on October 25, 2017

Approved on February 22, 2018
23. Feizollahzadeh S, Taheripanah R, Khani M, Farokhi B, Amani D. Promoter region polymorphisms in the transforming growth factor beta-1 (TGF $\beta 1$ ) gene and serum TGF_1 concentration in preeclamptic and control Iranian women. J ReprodImmunol. 2012; 94 (2): 216-21.

24. Borzychowski AM, Croy BA, Chan WL, Redman CW, Sargent IL. Changes in systemic type 1 and type $2 \mathrm{immu}$ nity in normal pregnancy and preeclampsia may be mediated by natural killer cells.European Journal of Immunology. 2005; 35 (10): 3054-63. 